\title{
Right of reply: Synthesis of a benchmark exercise for geotechnical analysis of a thermoactive pile
}

\section{Julien Habert}

Terrasol, Quai de la rapée, Paris, France (julien.habert@setec.com)

\section{Authors' reply}

The authors would first like to thank the commenting contribution.

The authors indeed hereby confirm that the results have to be analysed taking into account that the geotechnical model used for the benchmark is $(a)$ rather well known and $(b)$ made of poor to medium stiff sand.

For practitioners, in the case of geothermal piles, it is clear that for additional thermal stress in the pile itself, upper values of geotechnical resistances have to be considered, as they lead to higher thermal stress than lower values of geotechnical resistances (as indeed stated in the commenting contribution). This choice may also concern the stiffness of the surrounding ground.
In the meantime, the authors would also like to recall that characteristic lower values (characteristic as defined by Eurocodes) of ground mechanical properties still have to be used in order to assess the settlement of the pile and also additional stress in any connecting elements (beam, etc.).

To sum up, the choice of representative parameters for soil-structure interaction appears crucial in estimating the behaviour of thermoactive pile, and it is duly recommended to proceed with parametric studies to cover the effects of ground property uncertainties. 